\title{
TRANSFORMACIÓN DEL PAISAJE Y DE LA RED VIARIA EN LA COMUNIDAD DE MADRID DURANTE EL PERÍODO 1972 - 1982
}

\author{
(LANDSCAPE AND ROAD NETWORK TRANSFORMATION IN THE \\ COMMUNITY OF MADRID BETWEEN 1972 AND 1982)
}

\author{
Isabel Otero, $M^{a}$ Teresa Alcaide y M Jesús García \\ Departamento de Construcción y Vías Rurales. Universidad Politécnica de Madrid \\ ESPAÑA
}

\section{RESUMEN}

La incidencia del hombre sobre la naturaleza, cada vez más intensa, ofrece múltiples ejemplos de acciones regresivas: roturaciones, obras públicas, disposición de residuos etc..., que por su frecuencia y dimensión territorial alteran los paisajes y causan numerosos e importantes impactos sobre el medio; son acciones derivadas de politicas que para alcanzar sus objetivos precisan de una transformación generalizada del medio.

En este contexto, el presente articulo expone la metodología seguida $y$ los resultados obtenidos como fruto de una investigación que ha tenido, como objetivo prioritario, poner en relación la transformación experimentada por el paisaje de la Comunidad de Madrid, durante el periodo 1972-1982, con la evolución de la red de carreteras y los cambios en la accesibilidad de los distintos puntos del territorio registrados a lo largo de ese mismo periodo, cambios que son consecuencia directa de la politica de transportes desarrollada en la década en la cual se ha centrado el estudio.

\section{SUMMARY}

The increasingly intense influence of man on the environment offers numerous examples of regressive actions: plonghing, public works, disposition of wastes etc... which, due to their frequency and territorial dimensions, alter landscapes and cause many important impacts. These actions arise from different policies which require general transformation of the environment in order to reach their objectives.

In this context, the present article explains the methodology followed and the results obtained in a research whose principal purpose was to relate the transformation which the landscape of the Madrid Community underwent in the period between 19721982 with the road network evolution and the changes in accessibility to different points of the territory registered during this period. These changes happened as a direct consequence of the transport policy developed in the decade.

\subsection{INTRODUCCIÓN}

Hoy día pertenece casi al saber popular el hecho de que el paisaje está cambiando; en los últimos diez años se han llevado a cabo campañas educativas y publicitarias de diverso alcance, que han tratado de poner de manifiesto la realidad de los hechos.

Estos cambios se han producido muchas veces de forma paulatina, a lo largo de un período dilatado de tiempo, pero en otros muchos casos el cambio ha sido traumático, como ha ocurrido, por ejemplo, con la urbanización masiva de las costas o con las repoblaciones extensivas de especies exóticas que han venido a sustituir, en numerosas ocasiones, a un bosque autóctono rico y variado.

Las causas del cambio paisajístico y la degradación ambiental se atribuyen, generalmente, a catástrofes naturales o a hechos que vienen impuestos, sin que en la mayoría de los casos se intente un análisis serio de la cuestión. Existe una amplia relación de 
actuaciones humanas que pueden desencadenar o potenciar el proceso de cambio y degradación; hay también una serie de medios que son más sensibles o frágiles y donde una misma actuación puede producir un cambio de mayor importancia; hay, por último, una serie de catástrofes naturales que de vez en cuando degradan virtualmente cualquier medio o paisaje.

En determinados casos se puede hacer un buen seguimiento del proceso del cambio, pero generalmente las causas aparecen poco claras; BARROW (1991) cita como posibles causas de cambio y degradación las siguientes:
- Desastres naturales: la causa de la degradación son los procesos bio-físicos y actos fortuitos.

- Cambios poblacionales: la degradación se produce cuando el crecimiento de la población sobrepasa (o se sitúa por debajo de, en algunos casos) unos valores ambientales críticos.

- Desarrollismo: los recursos se explotan teniendo como meta prioritaria el beneficio económico, quedando en segundo plano los condicionantes ambientales.

- Tecnologías inapropiadas: el empleo de estrategias

Organigrama 1

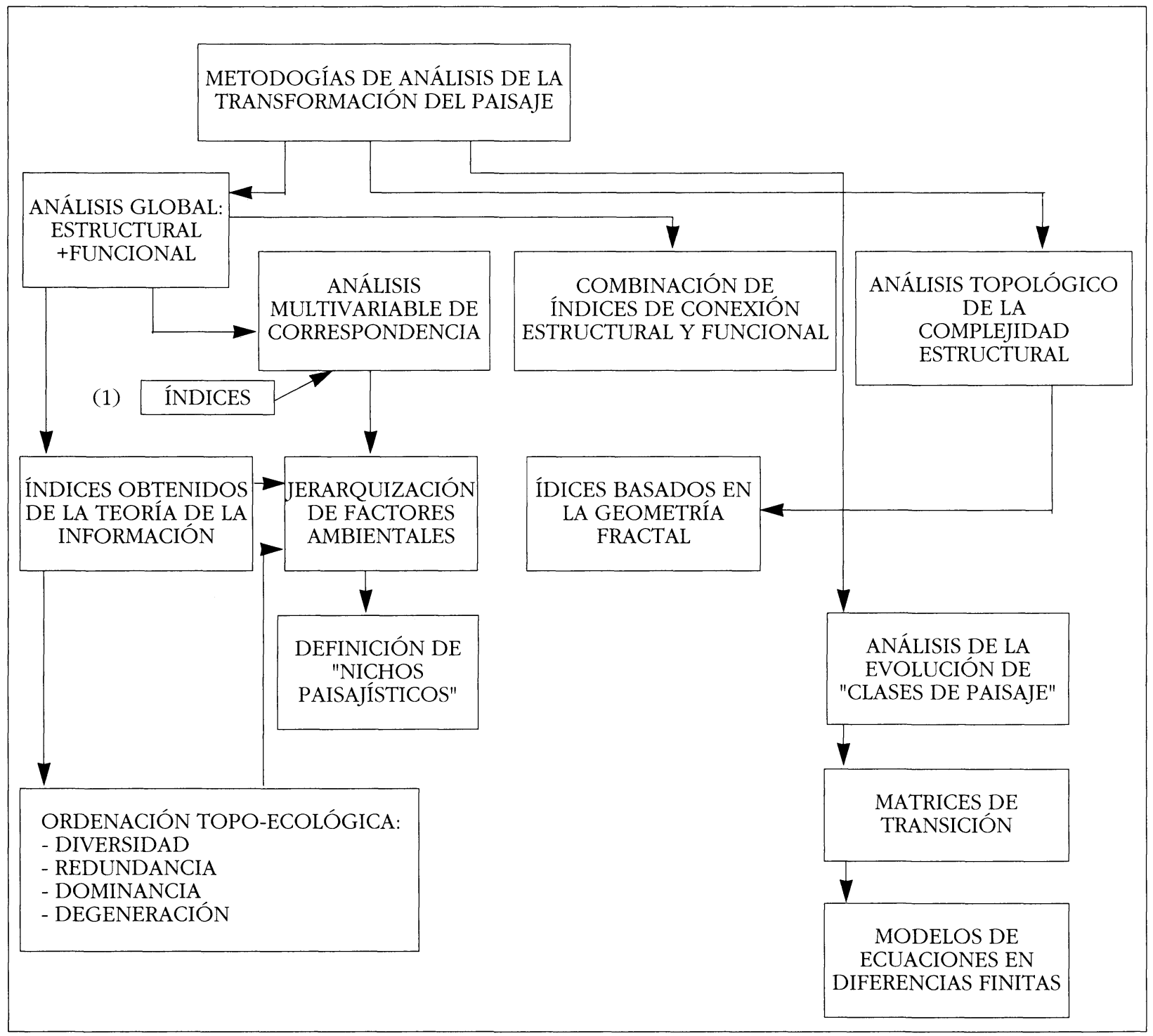

(1) Los índices pueden constituir un input en el análisis multivariable. 
y técnicas inadecuadas se traduce en una degradación ambiental.

- Falta de formación (conocimientos): la ignorancia sobre el alcance de una acción o de la utilización de un producto puede inducir cambios negativos en el paisaje.

- Actitudes: la actitud popular e institucional hacia el medio ambiente puede favorecer la degradación.

En función de la intensidad de estas acciones, se pueden diferenciar tres tipos de ciclos biogeoquímicos: natural, perturbado (transformado por las acciones humanas) y reciclado; el segundo tipo se encuentra en expansión, el último, en cambio, se da difícilmente.

En definitiva se puede decir que el cambio paisajístico y la degradación ambiental son el resultado de un proceso global, que se debe no sólo a causas puntuales y que, generalmente, es complejo. Cuando la escala del proceso global es amplio, se produce un estado de equilibrio dinámico que se trastoca fácilmente como consecuencia de las actividades humanas.

El análisis y medición del cambio paisajístico y de sus causas próximas o remotas, comienza hoy a ser objeto de estudio; dentro del campo de la ciencia del paisaje se ha realizado un considerable esfuerzo en la precisión de los conceptos y bases de partida, y en el desarrollo e implementación de metodologías orientadas a la determinación de la calidad y fragilidad paisajística. En cambio, las transformaciones en el paisaje no han sido, por el momento, objeto de análisis detenido debido a lo reciente de esta disciplina, por lo que no existe aún en este campo un cuerpo de doctrina suficientemente desarrollado. Existen, no obstante, varias líneas de trabajo iniciadas que se pueden relacionar tal y como aparecen en el organigrama 1.

A lo largo de este artículo se exponen la metodología seguida y los resultados obtenidos en el estudio del cambio paisajístico producido en la Comunidad de Madrid durante el período 1972-1982, y su comparación con la evolución de la red de carreteras durante este mismo período. La elección del período 1972-1982 como límite del estudio se ha debido a condicionantes en relación con la información básica disponible.

\subsection{METODOLOGIA}

Para la realización del estudio, objeto de este artículo, se ha seguido la metodología que se expone en el cuadro 1.

Cuadro 1

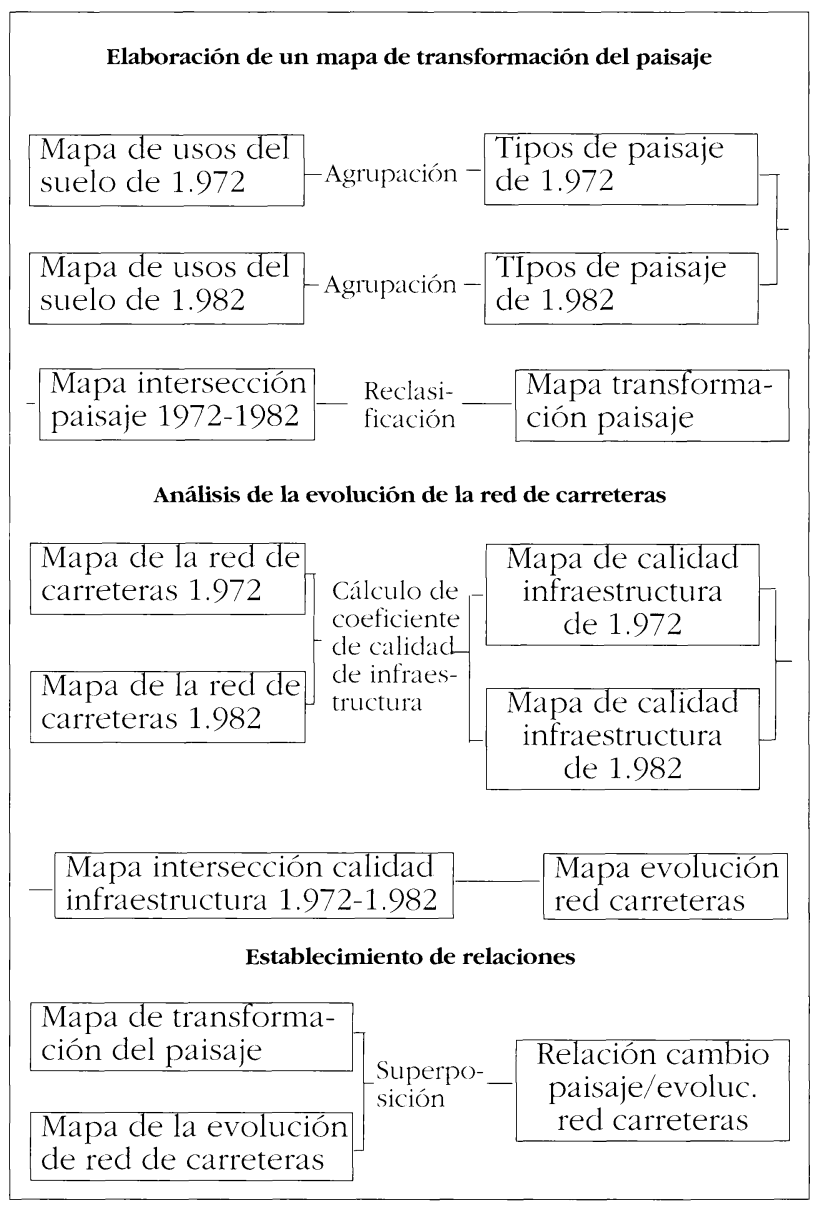

\subsubsection{ELABORACIÓN DEL MAPA DE TRANSFORMACIÓN DEL PAISAJE}

Tomando como base los mapas de usos del suelo de la Comunidad de Madrid de 1972 (Coplaco, 1974) y 1982 (varios autores, 1982), se ha elaborado lo que denominamos cartografía básica del paisaje a través del siguiente proceso:

- se busca como objetivo prioritario obtener un conjunto de unidades que puedan considerarse homogéneas desde el punto de vista paisajístico a la escala de trabajo utilizada (1:200.000); =

\section{$-$}

- para ello se realiza una agrupación de las unidades de vegetación y usos actuales del suelo en cada 
una de las dos épocas, refiriéndolas a un patrón común de unidades de paisaje al que se llega tras los pasos siguientes:

* Se han diferenciado en primer lugar cinco tipos de actividades antrópicas:

- núcleos urbanos, zonas afectadas por su expansión y urbanizaciones residenciales,

- zonas de actividades extractivas,

- embalses,

- pastos,

- cultivos;

dentro de este último tipo se diferenciaron los cultivos de regadío de los de secano, y del mosaico de secano y matorral, dada su heterogeneidad desde el punto de vista paisajístico; la localización de estos tres tipos de cultivos es, por otra parte, bastante característica.

* Dentro de las unidades correspondientes a vegetación arbórea se han establecido cuatro categorías o tipos de paisaje:

- formaciones de galería

- pinares

- frondosas de hoja caduca

- frondosas de hoja persistente.

Se decidió agrupar todas las especies de pino presentes en la Comunidad en una sola categoría, debido a que el tipo de paisaje resultante es de similares características conforme al objetivo buscado. Dentro de las frondosas, sin embargo, se distinguieron dos tipos ya que los cambios cromáticos de las frondosas de hoja caediza, según las estaciones, resulta ser un matiz de importancia en la caracterización del paisaje.

Las formaciones de galería se tratan como un tipo independiente dada su disposición característica en las márgenes de los ríos que, en la zona de transición y de los páramos, constituye un importante contraste con los cultivos de secano, los encinares y los matorrales.

Los matorrales de altura, los piornales, se han considerado asimismo como grupo independiente, dadas sus características diferenciales.

Se han tenido en cuenta, por último, un mosaico de pequeñas manchas de pastos, matorrales, rebollo, encinas y fresnos, que forman en su conjunto un paisaje homogéneo.
Hay, en definitiva, 14 tipos diferentes de paisaje, cuya denominación es la siguiente:

1. Formaciones en galería (riberas).

2. Cultivos de regadío.

3. Cultivos de secano.

4. Mosaico de secano y matorral.

5. Matorral.

6. Piornales y matorral de altura.

7. Pastizales.

8. Pinares.

9. Frondosas caducifolias.

10. Frondosas de hoja persistente.

11. Mosaico de pastos, prados, y rodales arbóreos y arbustivos.

12. Actividades extractivas.

13. Embalses.

30. Núcleos urbanos y urbanizaciones.

En el caso del mapa correspondiente a 1972, se consideró además otro tipo (O. Olivares), dado que la información existente así lo permitía. En 1982 los olivares se consideran como parte integrante del apartado de cultivos de secano.

Cada una de estas unidades o tipos de paisaje se pueden describir como sigue:

\section{1.-FORMACIONES EN GALERIA, RIBERAS Y ZONAS SOMETIDAS A INUNDACIONES PERIÓDICAS. (Foto1)}

Está representada en las cuatro grandes unidades fisiográficas de Madrid, pero resalta más en la zona de transición y en la depresión del Tajo.

Las especies que la componen son los chopos, sauces y alisos, además de rebollo y fresno.

\section{2.-CULTIVOS AGRÍCOLAS DE REGADÍO}

Gran parte de los cultivos de regadío se asientan en las terrazas del Manzanares, Henares, Tajuña, Jarama, Alberche y Tajo. En parcelas de tamaño y forma variados.

También aparecen en vegas más estrechas donde existe acumulación de arenas y elementos finos, al igual que en zonas donde la altura del nivel freático posibilita el aprovechamiento en regadío. 


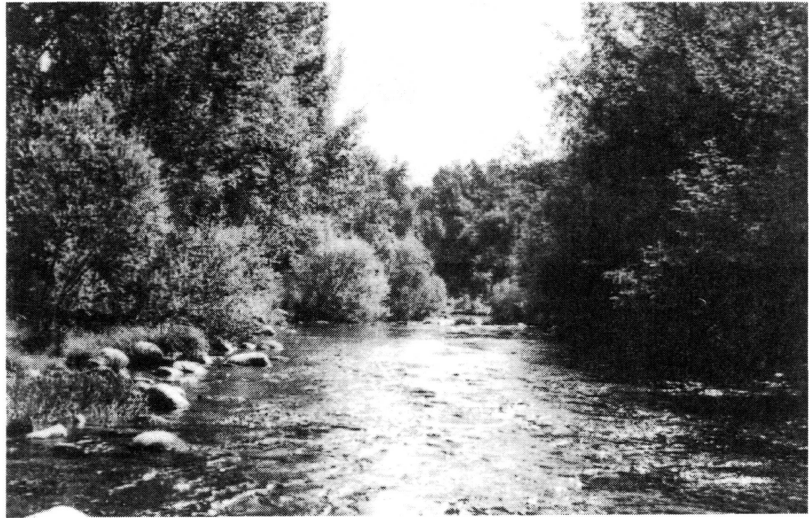

Foto 1.- Panorámica de bosque en galería

\section{3.-CULTIVOS AGRÍCOLAS DE SECANO}

Suponen el 90\% de las tierras dedicadas al cultivo. La distribución espacial del secano depende de la acción del hombre así como de la morfología, hidrología, edafología y clima. Se localizan tanto sobre las arcosas de la transición como en los sustratos básicos del Sur y sobre los depósitos cuaternarios.

En el páramo y superficies onduladas alternan olivares y viñedos, y extensiones de trigo y cebada.

En las arcosas los cultivos predominantes son trigo y cebada con olivos; en estas zonas el rendimiento es menor, resulta más frecuente encontrar matorral entre parcelas de cultivo y presencia aislada de encinas. En el Oeste y cercanas al pedimento aparecen dehesas claras de encina.

\section{4.-MOSAICO DE CULTIVOS AGRÍCOLAS DE SECANO Y MATORRALES}

En el Sur suele aparecer un mosaico de cultivos de trigo, cebada y/o olivos alternando con matorral calizo o gipsícola sobre los taludes y cuestas de los páramos, con baja productividad.

En zonas más abarrancadas y xerófilas, con taludes más desarrollados y degradados por erosión, los cultivos ocupan las vaguadas y el matorral se sitúa en las lomillas y laderas. También ocurre que el secano se sitúa en las pequeñas mesas.

\section{5.-MATORRALES}

Su presencia suele indicar que la acción humana ha incidido sobre formaciones arbóreas degradándolas.

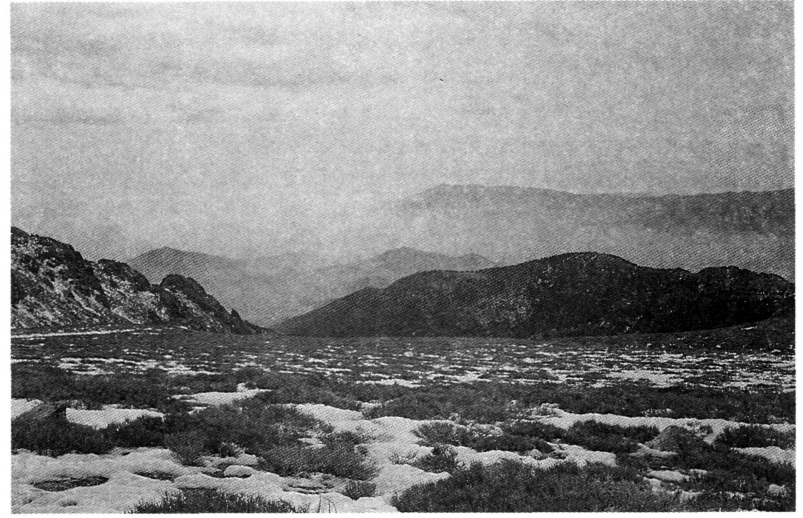

Foto 2.- Piornales y matorral de altura en la sierra madrilena.

Los matorrales alcanzan la condición de climáticos cuando el medio presenta circunstancias adversas, que no permiten la instalación de especies arbóreas, pues son más exigentes. Las condiciones adversas pueden deberse al clima, que cambia fundamentalmente con la altitud, y por ello se ha separado el piornal y otros matorrales de altura del resto de los matorrales.

Sobre sustratos básicos encontramos: aulaga, salvia, romero, esparto, jabuna, albardín y tomillo procedentes de la degradación de encinares, coscojares y quejigares. También pueden encontrarse como colonizadores de cultivos abandonados.

Los jarales, al igual que cantuesares y tomillares, ocupan la rampa y laderas de la sierra, pero representan etapas mas avanzadas en la regresión que la de las leguminosas. Suelen sustituir a la encina y el roble.

Los retamares se encuentran en la rampa serrana acompañados de encinas arbóreas y arbustivas, y también en margas y terrenos cuaternarios del Sur. Su mayor representación se da en arenas arcósicas.

Los brezales se asientan al Noreste de la provincia sobre pizarras, en el territorio potencial del roble albar, del haya y del melojo.

\section{6.-PIORNALES Y MATORRAL DE ALTURA}

Los piornales y matorrales de altura se asientan sin arbolado cubriendo el suelo donde la roca lo permite. 


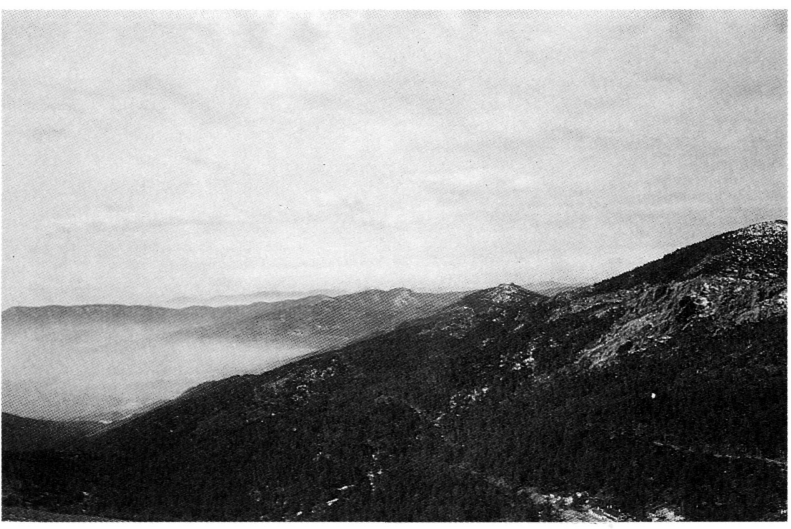

Foto 3.- Pinares de Pinus sylvestris en las laderas de la sierra.

\section{7.-PASTIZALES}

Se asientan en las zonas preserranas y serranas. Los pastos de altura son los que se corresponden con un estado más natural de la vegetación; el resto aparece debido a la explotación ganadera.

En el mapa sólo se señalan como pastizal las manchas mas extensas; las manchas pequeñas se han incluido en el mosaico abigarrado de pastos, prados y rodales arbóreos y arbustivos.

\section{8.-PINARES (Foto 3)}

En los pinares madrileños están representados casi todos los pinares peninsulares; unos son formaciones naturales y otros corresponden a repoblaciones artificiales. Ocupan una amplia banda en las laderas medias y altas de la sierra. Existen también manchas amplias de pinar tanto en la zona de transición como en la zona de páramos.

\section{9.-FRONDOSAS DE HOJA CADUCA}

En su mayor parte representadas en las laderas medias y bajas de la sierra. En el caso del melojo, éste desciende desde los $1.700 \mathrm{~m}$ hasta la rampa donde se mezcla con el fresno.

Se pueden señalar como formaciones singulares el robledal de la Hiruela y el hayedo de Montejo.

El castaño tiene su mejor representación al Suroeste de la provincia y en las laderas de las Machotas (El Escorial). El quejigo se suele mezclar con la encina y

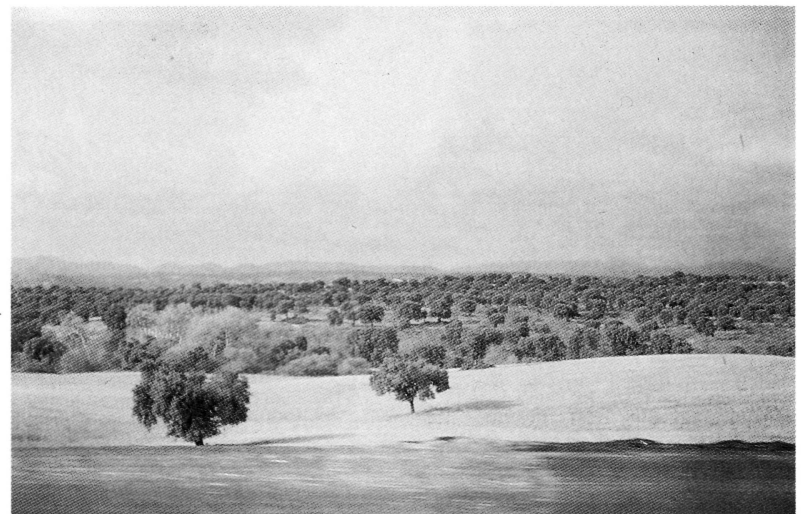

Foto 4.- Dehesa de encinas (formación de fiondosas persistentes), un claro exponente del paisaje mediterráneo.

la coscoja, y aparece tanto con porte arbóreo como arbustivo. También se mezcla con el fresno y melojo en ambientes más húmedos.

El fresno (Fraxinus angustifolia) se ubica en la zona basal de la sierra en formaciones monoespecíficas o mezclada con rebollo y encina. Requiere humedad para su desarrollo y suele aparecer también sobre pastos y en formaciones en galería.

\section{0:-FRONDOSAS DE HOJA PERSISTENTE (Foto 4)}

En esta clase se agrupan la encina (a la cual acompaña el enebro y la sabina), el alcornoque y la coscoja.

Se desarrollan principalmente sobre la rampa y en la zona de la transición. La encina ocupa zonas bastante extensas al Noroeste de la capital.

El enebro (Juniperus communis) es muy abundante en la provincia de Madrid, se presenta acompañando a pinos y sobre todo a la encina. No ocurre lo mismo con la sabina (Juniperus thuriphera), de la que existe una pequeña agrupación al Nordeste del embalse de La Pinilla. También puede aparecer mezclada con la encina.

El alcornoque se sitúa, principalmente al Suroeste de la provincia en forma de pequeños bosquetes. Como ejemplares aislados, aparece con mayor o menor intensidad mezclados con la encina.

Por último la coscoja aparece en el Sur y Sureste, en los bordes del páramo calizo, con ejemplares de poca talla y acompañando a encinares o matorrales subarbustivos. 


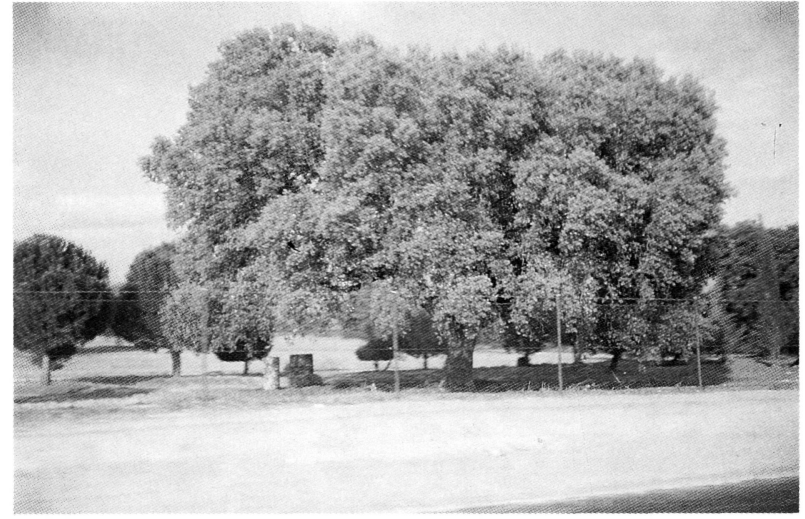

Foto 5.- Ejemplar centenario de encina, una imagen a perpetuar.

\section{1.-MOSAICO ABIGARRADO DE PASTOS, PRADOS Y RODALES ARBÓREOS Y ARBUSTIVOS}

Este mosaico reune pequeñas manchas de pastizales, encinas, melojo, fresno y matorral que no poseen significación cartográfica a la escala de trabajo como tales, sino que forman un paisaje homogéneo. Dependiendo de la altura, humedad y temperatura, aparecerán unas u otras especies, todas ellas dando lugar a formaciones del mismo aspecto.

Se sitúa básicamente en la zona Noreste de la provincia, si bien puede encontrarse también una banda que se extiende desde Somosierra hasta el embalse del Vellón, así como otra zona entre Cercedilla y el embalse de Santillana.

\section{2, 13 Y 30.- ACTIVIDADES EXTRACTIVAS, EMBAL- SES, Y NÚCLEOS URBANOS Y URBANIZACIONES}

Corresponden estas unidades a tipos de paisaje en los que se registra un alto grado de incidencia humana; las actividades extractivas están escasamente representadas, dado que su cartografía es prácticamente inviable a la escala de trabajo (1:200.000); no ocurre lo mismo, en cambio, con los núcleos urbanos y urbanizaciones, que ocupan una amplia extensión en el conjunto de la Comunidad de Madrid.

Una vez elaborados estos mapas de paisaje, se procedió a su digitalización e intersección mediante la utilización del sistema de información geográfica llamado PC.ARC/INFO (ESRI, 1992). La metodología seguida con este sistema se puede resumir en el cuadro 2.

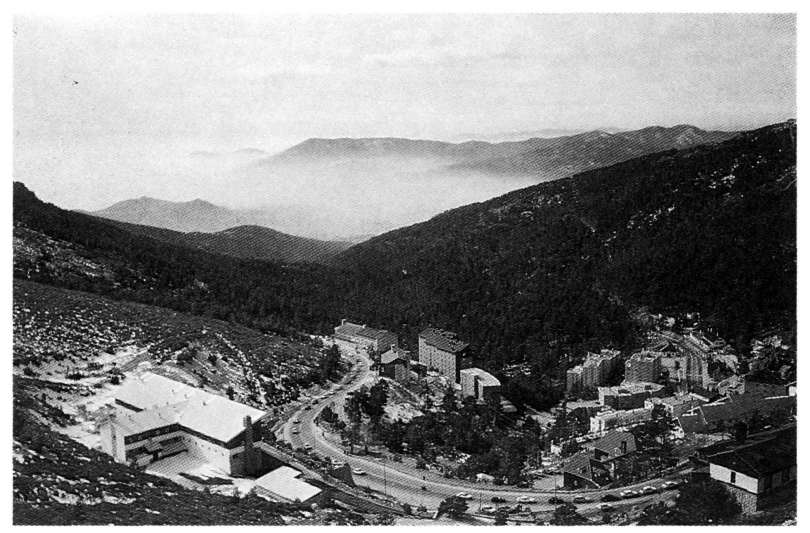

Foto 6.- La urbanización avanza, invadiendo parajes naturales,e induciendo importantes cambios en el paisaje (Puerto de Navacerrada).

Cada uno de los procesos se explica a continuación exponiendo los pasos seguidos de forma cronológica.

El primer paso a seguir (cuadro 3) es la preparación adecuada de los planos de paisaje que fueron elaborados; éste es un paso importante que merece atención pues de él depende que los datos introducidos tengan buena precisión y su corrección posterior sea sencilla y no genere problemas adicionales. Para ello es necesario eliminar todos aquellos elementos sobrantes o bien marcar claramente cuáles de los elementos gráficos son los que se deben introducir. Es necesario además mostrar con claridad y sin lugar a dudas cuáles son los valores de los atributos que corresponden a cada elemento gráfico y en qué posición deberán ir asociados a dichos elementos para que su posterior representación sea adecuada.

Cuadro 2

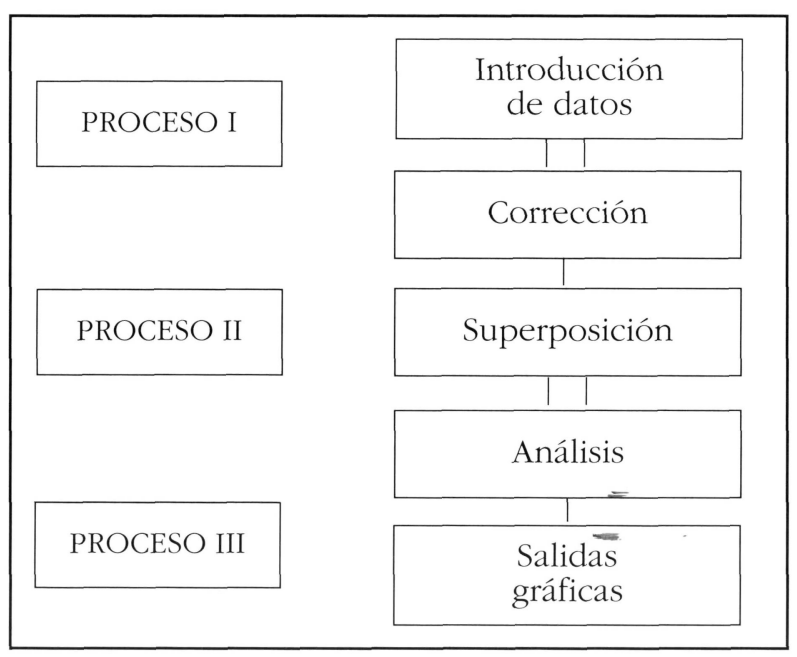




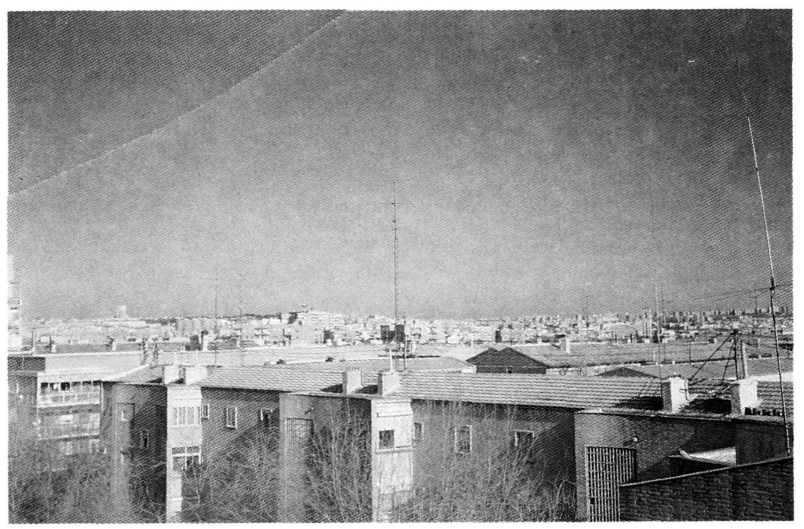

Foto 7.- La gran ciudad se extiende basiar del hrizanle.

Cuadro 3

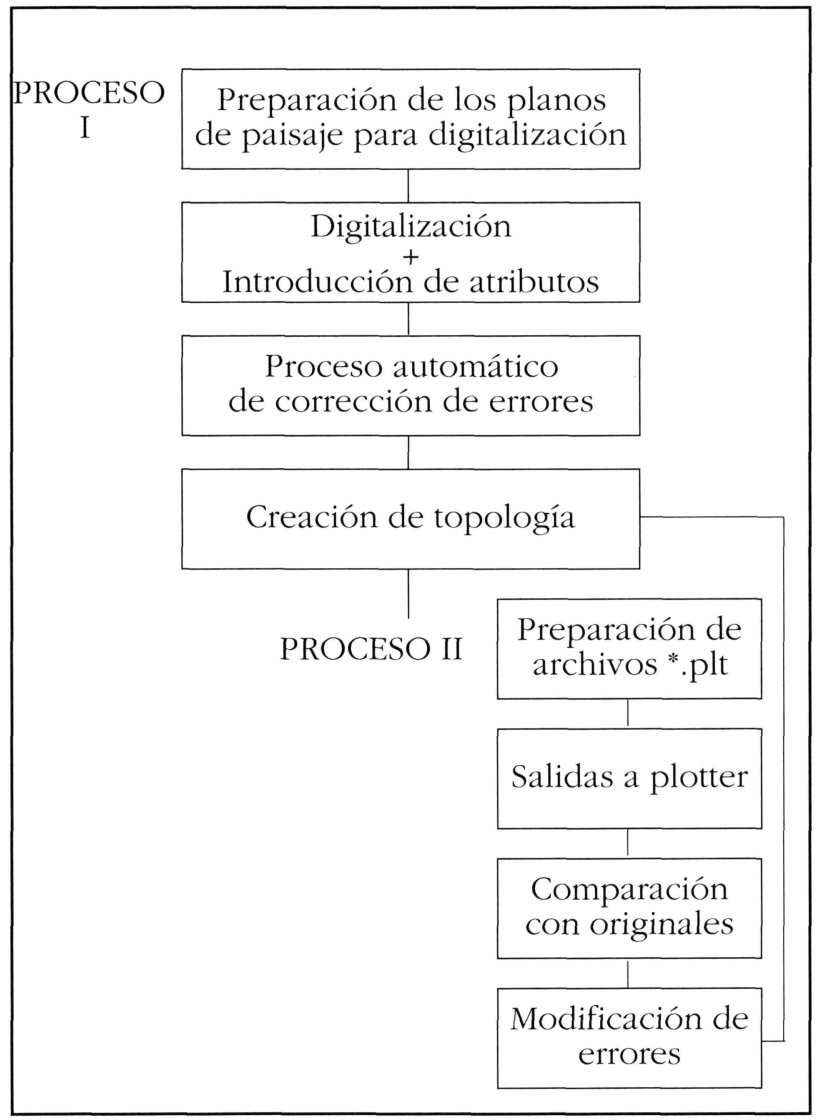

El proceso informático comienza con la introducción de los dos tipos de datos que se van a utilizar; se eligió digitalizar en primer lugar los arcos que forman los contornos de cada polígono, y a continuación se digitalizaron los lugares geométricos, dentro de cada polígono, donde se visualizan los atributos numéricos que llevan asociados, y se fueron introduciendo éstos simultáneamente. Los valores de dichos atributos se corresponden con los tipos de paisaje en los

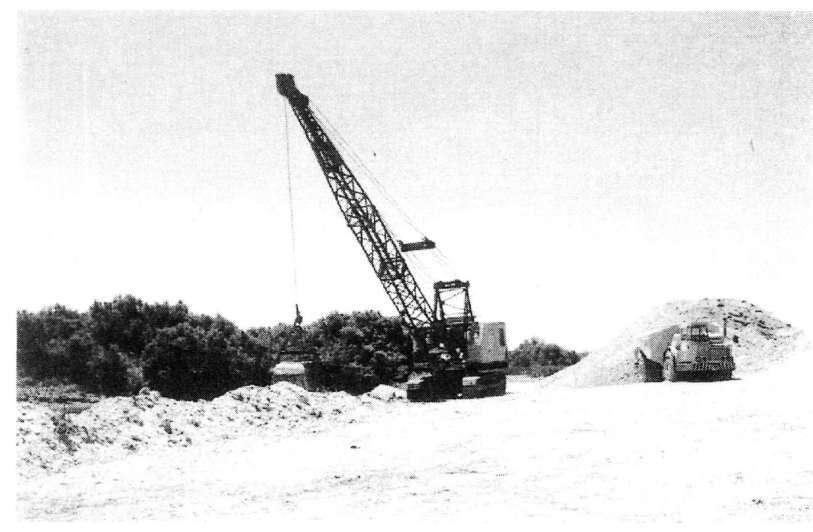

Foto 8.- Actividades extractivas en las márgenes del río Jarama.

distintos períodos de tiempo en estudio. Se decidió realizar la digitalización de manera que los arcos se cruzaran con otros arcos, asegurando de esta forma la existencia de conexión en el punto de cruce.

El siguiente paso consiste en la eliminación automática de los arcos generados por exceso en la digitalización.

Una vez acabado el proceso de introducción de datos se está en condiciones de crear topología, esto es, crear las relaciones por las que se define cada elemento cartográfico por medio de un conjunto de otros elementos; así se obtiene lo que llamamos una cobertura, en la que las relaciones y conexiones entre los recintos y sus atributos están aseguradas.

Es imprescindible en este momento hacer unas salidas por plotter y comprobar que los planos originales coinciden con los datos que hemos introducido. Los errores que presentan estas pruebas fueron corregidos editando tanto la información gráfica como las tablas de datos asociadas a ella, por lo que fue necesario crear de nuevo topología.

El resultado de todo este proceso son coberturas de la Comunidad Autónoma de Madrid, en las que se encuentran asociados los datos geográficos con los valores numéricos que representan los usos del suelo en los distintos períodos a analizar; están por consiguiente en condiciones de prestarnos una valiosa información una vez que sean cruzadas entre sí.

Este procedimiento de cruce se analiza a continuación y queda esquematizado en el cuadro 4. El proceso básico consiste en la superposición de las 
coberturas de paisaje para dar como resultado una cobertura única que refleja la evolución sufrida por el paisaje entre el año 72 y el 82. Esta superposición genera gran cantidad de nuevos polígonos que llevan asociados dos atributos distintos: el tipo de paisaje en el 72 y el tipo en el 82, lo que permite deducir cuál ha sido la evolución, tanto en magnitud del cambio, como en dirección, positiva o negativa, así como determinar su emplazamiento geográfico de forma inmediata.

En este momento se realiza el análisis, lo que obliga a hacer reclasificaciones, asociaciones, cálculo de índices, asociación de otros atributos, etc.

Con objeto de reflejar los resultados de este análisis se sacaron las tablas de cruce y, para ilustrarlas gráficamente, se editó en plotter el mapa de transformación del paisaje.

Para la realización de dicho mapa fueron necesarios unos procedimientos conducentes a la simplificación de la información gráfica generada. El proceso completo queda reflejado en el cuadro 5.

En primer lugar se realiza una agrupación en las diez clases de cambio de paisaje, de manera que polígonos adyacentes con el mismo valor de cambio se agrupan generando un polígono único.

En segundo lugar fue necesario suprimir recintos cuyo significado a la escala de trabajo es insignificante. Se procede entonces a su eliminación tanto gráfica como de la tabla de atributos mediante un proceso que es del todo informático. Cuando dichos polígonos son eliminados, su área se añade al polígono más grande con el que estén en contacto, por esta razón todos los polígonos que deben ser eliminados y estén en la periferia deben llevar un proceso alternativo, pues de lo contrario son añadidos al polígono exterior, restándose su área del área total de estudio y modificándose los límites de ésta.

Se eliminaron todos los polígonos con área inferior a 0.01 UD ARCINFO (unas 25 ha reales).

Para determinar el área mínima despreciable se consideró inicialmente un valor muy bajo que fue aumentado progresivamente, teniendo la precaución de no eliminar aquellos polígonos que, por su significado especial, como por ejemplo las formaciones en galería, debían permanecer a pesar de que su área total no fuese muy representativa.
Cuadro 4

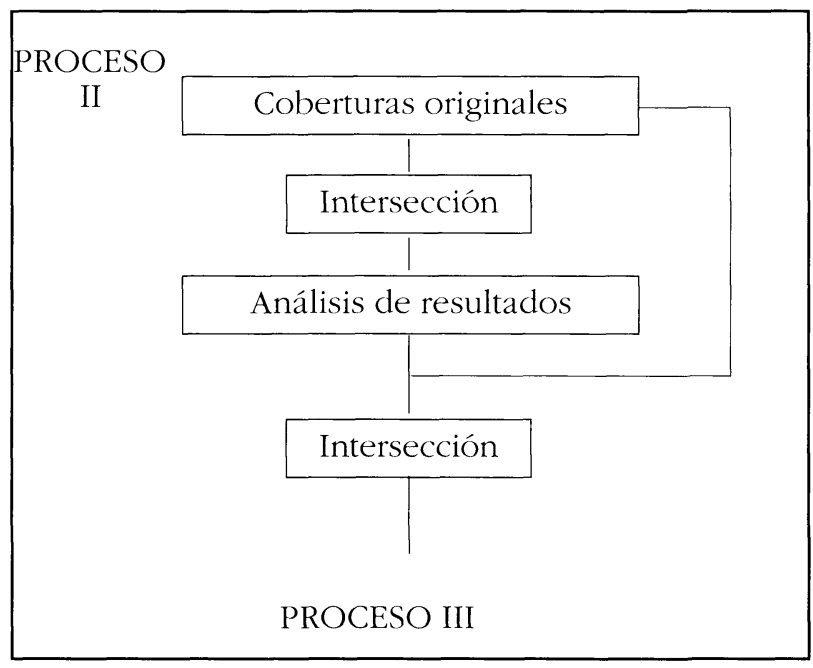

Cuadro 5

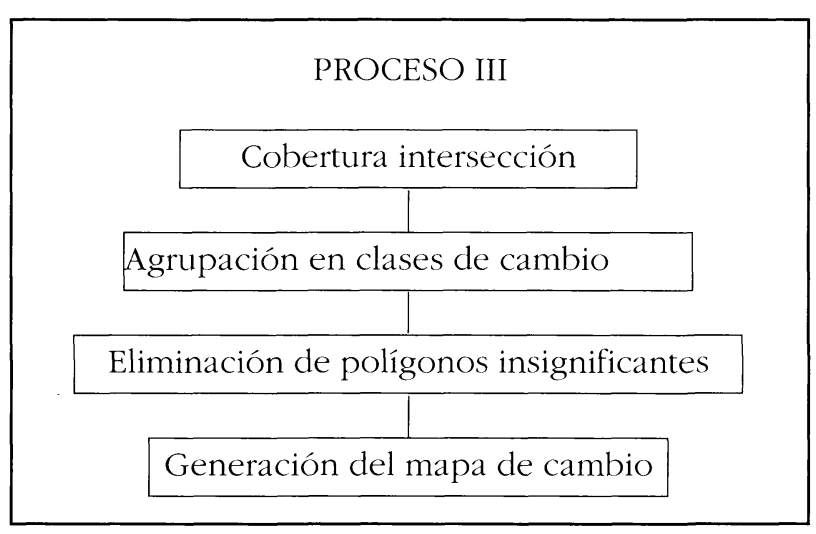

Cuadro 6

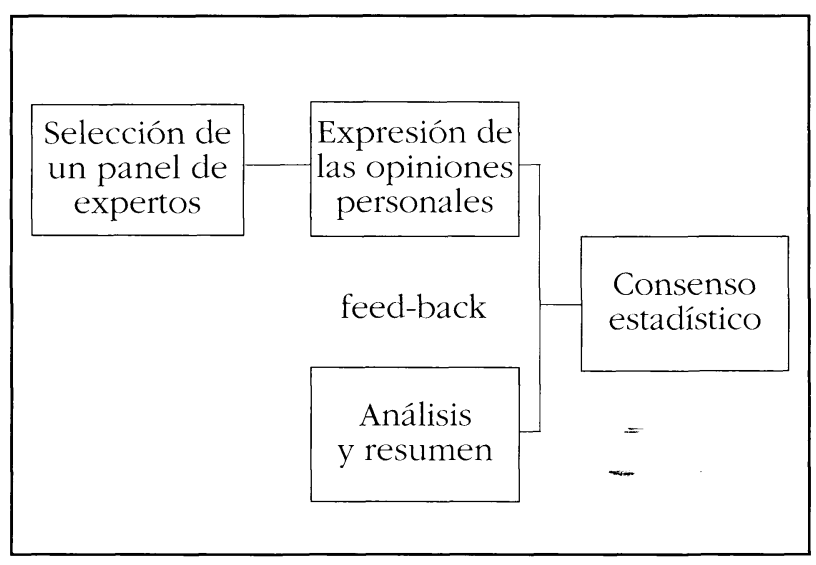


La generación del mapa se hizo teniendo en cuenta que debía ilustrar los cambios de paisaje producidos en el período de tiempo en estudio. Se eligieron colores rojos para los cambios negativos, y verdes para los positivos, indicando la intensidad del color la magnitud del cambio (mapa de transformación del paisaje).

Toda la información contenida en el mapa final se resume en una tabla de doble entrada o matriz en la que se compara cada tipo de paisaje del año 72 con cada tipo del 82, para evaluar así el cambio producido en cada situación (cuadro 7 y 7 bis).

Para la asignación de los valores de la matriz se ha seguido el método DELPHI (Helmer, 1966), que fue diseñado por los investigadores de la Rand Corporation y que resulta ser especialmente idóneo para resolver los conflictos derivados de la asignación de valores a descripciones cualitativas.

El método DELPHI es un método que explicita y refina opiniones autorizadas, opiniones de expertos; consta de las etapas expresadas en el cuadro 6 :

-selección de un panel de expertos en la materia en cuestión,

-cada miembro del panel contesta, separadamente y por escrito, a un cuestionario relativo al problema de que se trate (la matriz de cambio en nuestro caso),

-se confecciona un resumen de las respuestas y se entrega a cada panelista para que reconsidere su contestación;

-se converge en el consenso estadístico, tras realizar las rondas que se consideren necesarias.

El proceso iterativo supone admitir que cada etapa va a producir mejores resultados que la anterior, que se dará una cierta convergencia y que ésta se dirigirá hacia valores representativos de la realidad.

El resultado de este proceso de valoración se resume en el cuadro 7, cuya leyenda es la siguiente:

1. Cambio extremo negativo.

2. Cambio grande negativo.

3. Cambio moderado negativo.

4. Cambio leve negativo.

5. Cambio que no afecta a la calidad del paisaje.

6. No hay cambio.

7. Cambio leve positivo.

8. Cambio moderado positivo.

9. Cambio grande positivo.

10. Cambio extremo positivo.

El sentido positivo o negativo del cambio se entiende aquí en relación a la calidad del paisaje.

Cuadro 7

\begin{tabular}{|c|c|c|c|c|c|c|c|c|c|c|c|c|c|c|}
\hline \multirow{2}{*}{$\begin{array}{c}\text { TIPOS PAISAJE } \\
1972\end{array}$} & \multicolumn{14}{|c|}{ TIPOS DE PAISAJE, 1982} \\
\hline & & 1 & 2 & 3 & 4 & 5 & 6 & 7 & 8 & 9 & 10 & 11 & 12 & 13 \\
\hline \multicolumn{15}{|l|}{30} \\
\hline 0 Olivar & 9 & 2 & 3 & 5 & 8 & 9 & 3 & 3 & 8 & 8 & 8 & 1 & 1 & 1 \\
\hline 1 Riberas & 6 & 2 & 2 & 2 & 3 & 3 & 2 & 3 & 5 & 5 & 5 & 1 & 1 & 1 \\
\hline 2 Regadío & 9 & 6 & 4 & 8 & 8 & 9 & 5 & 9 & 9 & 9 & 9 & 1 & 5 & 1 \\
\hline 3 Secano & 9 & 8 & 6 & 8 & 8 & 9 & 8 & 9 & 9 & 9 & 9 & 1 & 5 & 1 \\
\hline $4 \mathrm{Sec} / \mathrm{Mat}$. & 9 & 3 & 4 & 6 & 8 & 8 & 3 & 9 & 9 & 9 & 9 & 1 & 1 & 1 \\
\hline 5 Matorr. & 8 & 3 & 3 & 3 & 6 & 7 & 3 & 8 & 9 & 9 & 9 & 1 & 1 & 1 \\
\hline 6 Piornal & 8 & 2 & 2 & 3 & 4 & 6 & 3 & 3 & 8 & 8 & 8 & 1 & 1 & 1 \\
\hline 7 Pastiz. & 9 & 5 & 3 & 8 & 8 & 8 & 6 & 9 & 9 & 9 & 9 & 1 & 1 & 1 \\
\hline 8 Pinar & 8 & 2 & 2 & 2 & 3 & 8 & 2 & 6 & 8 & 8 & 8 & 1 & 1 & 1 \\
\hline 9 Caducif. & 5 & 2 & 2 & 2 & 2 & 3 & 2 & 3 & 6 & 5 & 3 & 1 & 1 & 1 \\
\hline 10 Persis. & 5 & 2 & 2 & 2 & 2 & 3 & 2 & 3 & 5 & 6 & 3 & 1 & 1 & 1 \\
\hline 11 Mosaic. & 5 & 2 & 2 & 2 & 2 & 3 & 2 & 3 & 8 & 8 & 6 & 1 & 1 & 1 \\
\hline 12 Extrac. & 10 & 10 & 10 & 10 & 10 & 10 & 10 & 10 & 10 & 10 & 10 & 6 & 10 & 5 \\
\hline 13 Embal. & 10 & 5 & 10 & 10 & 10 & 10 & 10 & 10 & 10 & 10 & 10 & I & 6 & 1 \\
\hline
\end{tabular}

Valoración de los cambios habidos en el paisaje. 
Cuadro 7 bis

\begin{tabular}{|c|c|c|c|c|c|c|c|c|c|c|c|c|c|c|c|}
\hline \multirow{2}{*}{$\begin{array}{c}\text { USOS } \\
1972\end{array}$} & \multicolumn{15}{|c|}{ USOS, 1982} \\
\hline & & 1 & 2 & 3 & 4 & 5 & 6 & 7 & 8 & 9 & 10 & 11 & 12 & 13 & 30 \\
\hline 1 & 46 & 150 & 198 & 131 & 18 & 1 & 20 & 8 & 9 & 91 & 9 & 6 & 22 & 163 & 7.47 \\
\hline Riberas & 1.250 & 1.949 & 0.847 & 0.484 & 0.066 & 0.0001 & 1.454 & 0.032 & 0.118 & 0.374 & 0.223 & 0.013 & 0.125 & 0.537 & \\
\hline 2 & 76 & 42 & 44 & 12 & 6 & 0 & 0 & 4 & 0 & 4 & 0 & 13 & 9 & 72 & 3.16 \\
\hline Regadío & 0.160 & 1.996 & 0.458 & 0.038 & 0.015 & 0 & 0 & 0.002 & 0 & 0.005 & 0 & 0.054 & 0.015 & 0.425 & \\
\hline 3 & 95 & 150 & 114 & 105 & 18 & 0 & 8 & 11 & 3 & 73 & 4 & 8 & 2 & 297 & 28.6 \\
\hline Secano & 0.176 & 1.597 & 19.244 & 3.758 & 0.496 & 0 & 0.150 & 0.208 & 0.026 & 0.400 & 0.208 & 0.085 & 0.0002 & 2.300 & \\
\hline 4 & 10 & 46 & 61 & 38 & 13 & 2 & 7 & 57 & 7 & 33 & 18 & 4 & 28 & 91 & 8.50 \\
\hline Sec/Mat. & 0.020 & 0.344 & 1.100 & 3.203 & 0.738 & 0.032 & 0.486 & 0.399 & 0.033 & 0.351 & 1.297 & 0.055 & 0.040 & 0.402 & \\
\hline 5 & 5 & 42 & 61 & 23 & 16 & 14 & 9 & 39 & 12 & 19 & 20 & 3 & 16 & 72 & 8.39 \\
\hline Matorr. & 0.009 & 0.190 & 0.371 & 1.840 & 1.608 & 0.484 & 0.190 & 0.694 & 0.096 & 0.851 & 1.693 & 0.004 & 0.022 & 0.333 & \\
\hline 6 & 0 & 0 & 0 & 0 & 1 & 5 & 1 & 21 & 10 & 0 & 1 & 0 & 0 & 3 & 1.30 \\
\hline Piornal & 0 & 0 & 0 & 0 & 0.051 & 0.834 & 0.0008 & 0.251 & 0.042 & 0 & 0.104 & 0 & 0 & 0.015 & \\
\hline 7 & 0 & 1 & 0 & 0 & 3 & 0 & 8 & 4 & 2 & 6 & 4 & 0 & 0 & 22 & 1.02 \\
\hline Past & 0 & 0.027 & 0 & 0 & 0.041 & 0 & 0.485 & 0.042 & 0.217 & 0.120 & 0.024 & 0 & 0 & 0.064 & \\
\hline 8 & 2 & 7 & 7 & 27 & 31 & 34 & 21 & 27 & 21 & 13 & 26 & 0 & 15 & 27 & 6.62 \\
\hline Pin. & 0.001 & 0.010 & 0.061 & 0.102 & 0.454 & 0.333 & 0.289 & 4.907 & 0.106 & 0.084 & 0.146 & 0 & 0.031 & 0.093 & \\
\hline 9 & 0 & 1 & 4 & 4 & 8 & 4 & 35 & 11 & 3 & 15 & 14 & 0 & 21 & 30 & 4.07 \\
\hline Caducif. & 0 & 0.00006 & 0.076 & 0.029 & 0.125 & 0.019 & 0.745 & 0.001 & 0.520 & 1.890 & 0.420 & 0 & 0.026 & 0.113 & \\
\hline 10 & 39 & 16 & 62 & 24 & 8 & 0 & 26 & 6 & 2 & 30 & 0 & 0 & 20 & 81 & 7.32 \\
\hline Persist. & 0.102 & 0.058 & 0.739 & 0.460 & 0.153 & 0 & 0.313 & 0.054 & 0.003 & 4.988 & 0 & 0 & 0.010 & 0.427 & \\
\hline 11 & 24 & 11 & 23 & 15 & 32 & 16 & 39 & 56 & 16 & 47 & 26 & 1 & 27 & 144 & 13.1 \\
\hline Mosaico & 0.052 & 0.038 & 0.511 & 0.578 & 0.726 & 0.206 & 2.500 & 1.528 & 1.354 & 2.188 & 2.598 & 0.010 & 0.033 & 0.720 & \\
\hline 12 & 0 & 0 & 0 & 0 & 0 & 0 & 0 & 0 & 0 & 0 & 0 & 0 & 0 & 0 & 0 \\
\hline Extract & 0 & 0 & 0 & 0 & 0 & 0 & 0 & 0 & 0 & 0 & 0 & 0 & 0 & 0 & \\
\hline 13 & 8 & 14 & 0 & 1 & 11 & 0 & 8 & 26 & 4 & 21 & 29 & 0 & 22 & 18 & 0.75 \\
\hline Embalse & 0.013 & 0.068 & 0 & 0.0001 & 0.015 & 0 & 0.018 & 0.022 & 0.005 & 0.016 & 0.030 & 0 & 0.546 & 0.021 & \\
\hline 30 & 22 & 73 & 146 & 59 & 30 & 1 & 82 & 37 & 14 & 88 & 30 & 8 & 14 & 233 & 6.76 \\
\hline Urbano & 0.044 & 0.131 & 0.507 & 0.129 & 0.087 & 0.001 & 0.210 & 0.080 & 0.050 & 0.210 & 0.081 & 0.026 & 0.005 & 5.202 & \\
\hline 0 & 4 & 22 & 23 & 48 & 12 & 1 & 2 & 4 & 2 & 21 & 1 & 0 & 0 & 15 & 2.90 \\
\hline Olivar & 0.0003 & 0.116 & 1.829 & 0.726 & 0.005 & 0.0004 & 0.00006 & 0.013 & 0.00001 & 0.025 & 0.00002 & 0 & 0 & 0.186 & \\
\hline TOTAL & 1.827 & 6.530 & 25.743 & 11.350 & 4.580 & 1.909 & 6.842 & 8.233 & 2.571 & 11.502 & 6.824 & 0.247 & 0.853 & 10.840 & \\
\hline
\end{tabular}

Número de polígonos y porcentaje de superficie madrileña de cada cambio.

En el cuadro 7 bis aparecen el número de polígonos y el porcentaje de superficie de cada caso. En este cuadro puede observarse que el mayor porcentaje de superficie corresponde a terrenos que, siendo cultivos de secano en 1972, no cambian de uso (un $19,24 \%$ de la Comunidad). En su conjunto, la superficie madrileña que no cambia de uso es un $47,4 \%$, una cifra relativamente baja considerando un período de tiempo tan corto (10 años).

Del 52,6\% restante, los cambios más significativos corresponden al paso de cultivo de secano a mosaico de secano y matorral $(3,76 \%)$ debido probablemente al abandono de cultivos y a la invasión por parte del de especies arbustivas.

Es significativo el aumento de terreno de regadío en más del doble procedente de formaciones de galería $(1,95 \%)$ y de los cultivos de secano $(1,60 \%)$ por estar próximos a los ríos o por irrigación artificial.

Las formaciones de galería disminuyen notablemente en este decenio. Los cultivos de secano también lo hacen y pasan a ser, entre otros usos, suelo urbano $(2,3 \%)$. El suelo de uso urbano aumenta también gracias a todos los demás usos, aunque en menor proporción.

La superficie de pastizales se ve incrementada grandemente por la disminución del uso "mosaico abigarrado de pastos, formaciones arbustivas y rodales arbóreos" $(2,5 \%)$ y del de formaciones de galería (1,45\%) principalmente. La disminución del mosaico abigarrado es debido además a su transformación en pinares $(1,53 \%)$, frondosas caducifolias $(1,35)$ y frondosas persistentes $(2,19 \%)$, por la mayo-rentabilidad económica de los pastizales o los pinares, o por el abandono que permite el desarrollo del arbolado. 
El aumento de las actividades extractivas y los embalses es de poca cuantía.

Por lo que se refiere a la localización espacial de las diferentes zonas y a la vista del mapa final de transformación del paisaje obtenido, se pueden realizar las observaciones siguientes:

1) Los CAMBIOS EXTREMOS NEGATIVOS corresponden fundamentalmente a un uso de suelo que pasa de ser agrícola de secano a urbano. Esto ocurre en las zonas consideradas como ciudades dormitorio: Alcorcón, Leganés, Parla y Fuenlabrada, al Sur de la Comunidad; Alcobendas y Barajas, al Norte y Alcalá de Henares, al Este. El hoy en día municipio de Tres Cantos también sufre en el período 72-82 un incremento de su zona urbana donde antes había pastizales.

En la zona Oeste y Noroeste de la provincia los cambios extremos negativos se producen en zonas de mucha menos extensión: hay un escaso aumento de zona urbana. Sólo destaca el cambio sufrido en la zona correspondiente al embalse de Valmayor, construido en 1975, y el embalse de Las Nieves (Parquelagos), de 1972. También aquí existen pequeños enclaves que pasaron de formación de frondosas persistentes a urbano, como ocurre en Torrelodones, y de pastizal a urbano en el alto Guadarrama (Cercedilla, Navacerrada, Guadarrama, etc.).

2) Los CAMBIOS GRANDES NEGATIVOS se producen en zonas que en 1972 eran formaciones en galería y que se convirtieron en cultivos de regadío; éstas se sitúan en las riberas del Tajuña, Tajo y afluentes del Jarama como el Arroyo de Anchuelo. En el Valle del Lozoya existe una pequeña mancha que pasó de formación en galería o mosaico de pastizal, matorral y rodales arbóreas a pastizal.

También tiene lugar un cambio negativo grande en dos zonas concretas:

a).-Zona Noroeste: desde Navacerrada y Villalba hasta Soto del Real y Tres Cantos, donde el cambio fue desde una formación de frondosas caducifolias (rebollares) a pastizales o mosaico abigarrado de pastizales, matorrales $y$ rodales arbóreos, fruto del aclaramiento de los rebollares.

b).-Alrededores de Valdemorillo-Villanueva del

(c) Consejo Superior de Investigaciones Científicas

Licencia Creative Commons 3.0 España (by-nc)
Pardillo y Chapinería, donde las formaciones de frondosas, caducifolias o persistentes se convirtieron en matorral, cultivos de secano o pastizales, por la creciente eliminación del arbolado.

3) Hay una zona más o menos extensa de CAMBIO MODERADO NEGATIVO al Sureste de la Comunidad; aquí tuvo lugar un cambio de olivar a secano, o de matorral a mosaico de cultivos y matorral, probablemente por el abandono de cultivos.

En Valdemaqueda (cercano a Hoyo de Pinares, Ávila), el paso fue de mosaico de pastizales, matorral y rodales arbóreos a pinar, y en los alrededores del embalse de El Vellón hay zonas que cambiaron desde formaciones de frondosas caducifolias a mosaico de pastizales, matorral y rodales arbóreos, y de mosaico de cultivos y matorral a pastizal, siempre por la desaparición del arbolado.

4) Los CAMBios EXTREmos positivos son muy escasos y su localización es muy concreta: zonas puntuales de Aravaca, el Real Club Puerta de Hierro (pasó de urbano a formaciones de frondosas persistentes), y los alrededores de la Base Aérea de Torrejón.

5) Hubo CAMBIOS GRANDES POSITIVOS en una amplia zona enmarcada entre S.Agustín de Guadalix, Miraflores de la Sierra, Buitrago y Torrelaguna. En esta parte ha habido cambios desde pastizales $\mathrm{y} / \mathrm{o}$ matorrales hasta formaciones de frondosas, caducifolias o persistentes. Esto puede ser debido al abandono de los recursos ganaderos que mantenían el pastizal y el matorral o monte bajo por la disminución de la población rural; en algún caso se ha realizado una conversión de monte bajo a monte alto.

En las fincas adyacentes al tramo de carretera que une Guadarrama con El Escorial, ha habido un cambio grande positivo al pasar de pastizales a formación de frondosas caducifolias, debido probablemente a la transformación de terrenos agropecuarios en fincas dedicadas a la caza.

En Fuentidueña de Tajo, al Sureste de la Comunidad, hay una zona que se transforma de olivar a pinar, y en Perales de Tajuña-Valdelaguna y Loeches hay un cambio de matorral o mosaico de cultivos con matorral a formación de frondosas persistentes. 


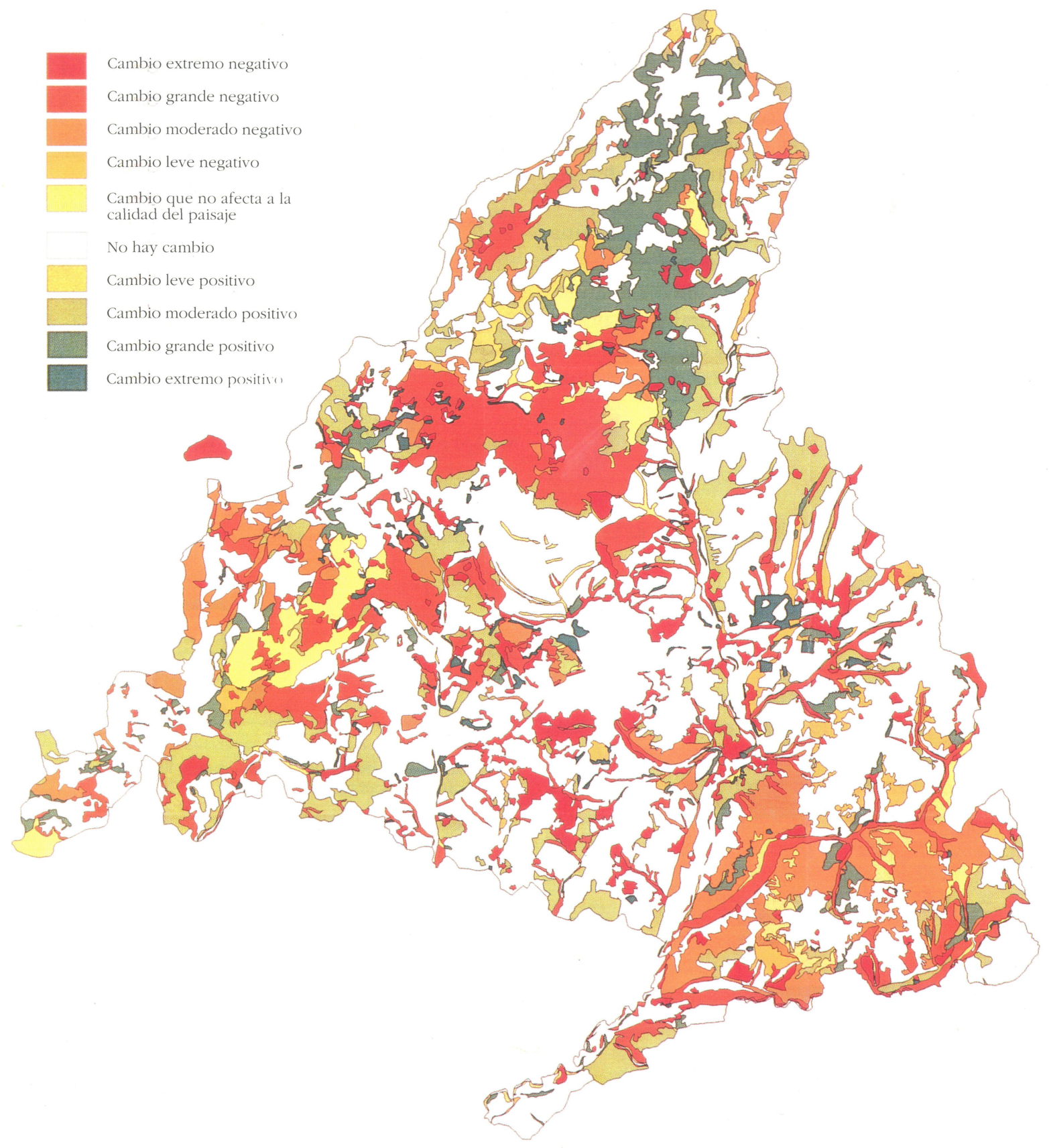

Transformación del paisaje en la Commindad Autónoma de Madrid (periodo 1972-1982). 
6) Los CAMBIOS MODERADOS POSITIVOS tienen lugar en zonas que pasan de cultivos de secano a mosaico de cultivos con matorral, por el abandono de la agricultura, en zonas como Navalcarnero, la ribera del Alberche, cercanías de El Casar de Talamanca (Guadalajara) o Torrelaguna.

En definitiva, puede decirse que en la Comunidad de Madrid ha habido pocos cambios extremos positivos (tan sólo un 1,5\%) y los cambios extremos negativos son más abundantes (6,1). El mayor porcentaje del terreno que cambia de tipo de paisaje resulta ser grande negativo (un 12,3\%), debido a la desaparición de zonas arboladas, mientras que existe una proporción análoga de cambios moderados positivos (un 12\%), a causa de la invasión de cultivos abandonados por parte de formas más naturales (matorrales). En cualquier caso hay un 46,7\% de terreno de la Comunidad que mantiene la misma calidad paisajística en el período 1972-82.

\subsubsection{ANÁLISIS DE LA EVOLUCIÓN DE LA RED DE CARRETERAS}

Para la elaboración de este mapa se han dado los siguientes pasos:

En primer lugar, se ha calculado para cada uno de los tipos de paisaje anteriores, y en las dos épocas consideradas, un coeficiente de calidad de infraestructura que es función de la longitud y calidad de la red viaria, y cuya expresión es la siguiente:

$\mathrm{I}=\left(\mathrm{l}_{\mathrm{A}} \cdot 3+\mathrm{l}_{\mathrm{B}} \cdot 1+\mathrm{1}_{\mathrm{C}} \cdot 0,75\right) \cdot 1 / \mathrm{S}$

donde 1: longitud de:

A: autopista,

B: carretera nacional,

C: carretera comarcal y local,

S: superficie de la unidad en estudio, que en este caso es cada una de las manchas o polígonos de paisaje.

- Una vez calculado este coeficiente se han agrupado los polígonos de paisaje, a los cuales se refiere la información, en clases según el cuadro 8, obteniendo los mapas de calidad de infraestructura 1972 y 1982, divididos en 5 y 6 clases respectivamente.
Cuadro 8

\begin{tabular}{|c|c|c|}
\hline \multirow{2}{*}{$\begin{array}{c}\text { VALOR DEL } \\
\text { COEFICIENTE }\end{array}$} & \multicolumn{2}{|c|}{ CLASES DECALIDAD INFRAESTR. } \\
\cline { 2 - 3 } & CLASE 1972 & CLASE 1982 \\
\hline$<16$ & 1 & 1 \\
\hline $17-33$ & 2 & 2 \\
\hline $34-50$ & 3 & 3 \\
\hline $51-67$ & 4 & 4 \\
\hline $67-84$ & 5 & 5 \\
\hline$>84$ & - & 6 \\
\hline
\end{tabular}

Cuadro 9

CLASES DE CALIDAD DE INFRAESTRUCTURA, 1982 CLASES DE

\begin{tabular}{|c|c|c|c|c|c|c|}
\hline \multicolumn{7}{|l|}{ CALIDAD } \\
\hline 1972 & & 1 & 2 & 3 & 4 & 56 \\
\hline 1 & 1 & 2 & 3 & 4 & 4 & 5 \\
\hline 2 & & 1 & 2 & 3 & 4 & 5 \\
\hline 3 & & & 1 & 2 & 3 & 4 \\
\hline 4 & & & & 1 & 2 & 4 \\
\hline 5 & & & & & 1 & 3 \\
\hline
\end{tabular}

Valor de cambio de infraestructura donde los valores inferiores significan lo siguiente:

1: no hay cambio; 2: cambio leve;

3: cambio moderado; 4: cambio grande;

5: cambio extremo.

Cuadro 9 bis

\begin{tabular}{|c|r|c|}
\hline $\begin{array}{c}\text { VALOR DE } \\
\text { CAMBIO }\end{array}$ & \multicolumn{1}{c|}{ ÁREA } & $\begin{array}{c}\text { № } \\
\text { POLÍGONOS }\end{array}$ \\
\hline 1 & $98.71 \%$ & 4906 \\
\hline 2 & $1.06 \%$ & 213 \\
\hline 3 & $0.19 \%$ & 112 \\
\hline 4 & $0.003 \%$ & $=17$ \\
\hline 5 & $0.0004 \%$ & - \\
\hline
\end{tabular}

Cambio de infraestructura. 
Cuadro 10

\begin{tabular}{|c|c|c|c|c|c|c|c|c|c|c|}
\hline \multirow{2}{*}{$\begin{array}{c}\text { CLASES DE } \\
\text { CAMBIO } \\
\text { DE } \\
\text { INFRA. }\end{array}$} & \multicolumn{10}{|c|}{ CLASES DE CAMBIO DEL PAISAJE } \\
\hline & 1 & 2 & 3 & 4 & 5 & 6 & 7 & 8 & 9 & 10 \\
\hline 1 & $\begin{array}{l}1209 \\
6.100\end{array}$ & $\begin{array}{c}871 \\
12.290\end{array}$ & $\begin{array}{c}397 \\
8.380\end{array}$ & $\begin{array}{c}103 \\
1.577\end{array}$ & $\begin{array}{c}249 \\
3.530\end{array}$ & $\begin{array}{c}514 \\
46.65\end{array}$ & $\begin{array}{c}14 \\
0.005\end{array}$ & $\begin{array}{c}561 \\
11.96\end{array}$ & $\begin{array}{c}462 \\
6.316\end{array}$ & $\begin{array}{c}526 \\
1.400\end{array}$ \\
\hline 2 & $\begin{array}{c}6 \\
0.005\end{array}$ & $\begin{array}{c}14 \\
0.004\end{array}$ & $\begin{array}{c}5 \\
0.0004\end{array}$ & $\begin{array}{c}3 \\
0.0003\end{array}$ & $\begin{array}{c}3 \\
0.0004\end{array}$ & $\begin{array}{c}59 \\
0.006\end{array}$ & $\begin{array}{l}0 \\
0\end{array}$ & $\begin{array}{c}6 \\
0.00003\end{array}$ & $\begin{array}{c}5 \\
0.0002\end{array}$ & $\begin{array}{c}112 \\
0.002\end{array}$ \\
\hline 3 & $\begin{array}{c}2 \\
0.0003\end{array}$ & $\begin{array}{c}6 \\
0.0002\end{array}$ & $\begin{array}{c}2 \\
0.00007\end{array}$ & $\begin{array}{l}0 \\
0\end{array}$ & $\begin{array}{c}5 \\
0.0001\end{array}$ & $\begin{array}{c}28 \\
0.0009\end{array}$ & $\begin{array}{l}0 \\
0\end{array}$ & $\begin{array}{l}0 \\
0\end{array}$ & $\begin{array}{l}0 \\
0\end{array}$ & $\begin{array}{c}68 \\
0.0006\end{array}$ \\
\hline 4 & $\begin{array}{l}0 \\
0\end{array}$ & $\begin{array}{l}0 \\
0 \\
\end{array}$ & $\begin{array}{l}0 \\
0 \\
\end{array}$ & $\begin{array}{l}0 \\
0 \\
\end{array}$ & $\begin{array}{l}0 \\
0\end{array}$ & $\begin{array}{c}7 \\
0.0002 \\
\end{array}$ & $\begin{array}{l}0 \\
0\end{array}$ & $\begin{array}{l}0 \\
0 \\
\end{array}$ & $\begin{array}{l}0 \\
0\end{array}$ & $\begin{array}{c}10 \\
0.0001\end{array}$ \\
\hline 5 & $\begin{array}{l}0 \\
0\end{array}$ & $\begin{array}{l}0 \\
0\end{array}$ & $\begin{array}{l}0 \\
0\end{array}$ & $\begin{array}{l}0 \\
0\end{array}$ & $\begin{array}{l}0 \\
0\end{array}$ & $\begin{array}{c}2 \\
0.00001\end{array}$ & $\begin{array}{l}0 \\
0\end{array}$ & $\begin{array}{l}0 \\
0\end{array}$ & $\begin{array}{l}0 \\
0\end{array}$ & $\begin{array}{c}2 \\
0.00003\end{array}$ \\
\hline
\end{tabular}

Número de polígonos y porcentaje de superficie.

Se han combinado, por último, estos dos mapas a través de la matriz del cuadro 9, obteniéndose como resultado un mapa final de evolución de la red de carreteras.

En el cuadro 9 bis aparecen el número de polígonos y porcentaje de superficie de cada combinación.

\subsubsection{ESTABLECIMIENTO DE RELACIONES}

Mediante la superposición de los dos mapas anteriores, y dado que tanto los datos de cambio de paisaje como los de evolución de la red de carreteras están referidas a las mismas superficies, polígonos de paisaje del mapa intersección $72 / 82$, se obtiene finalmente la relación entre el cambio de paisaje y la evolución de la red de carreteras tal y como queda resumido en el cuadro 10, donde aparece el número de polígonos y el porcentaje de superficie de cada caso.

\subsection{CONCLUSIONES}

1: El índice de calidad de infraestructura utilizado no permite en nuestro caso detectar grandes diferencias entre las dos épocas consideradas: la mayor parte de la superficie se sitúa en el valor de cambio de infraestructura 1. Sería por tanto aconsejable utilizar en este tipo de estudios, en los que no se considera un período de tiempo muy dilatado, algún otro tipo de índice que tenga un mayor poder discriminatorio.

2: Por lo que se refiere a la relación entre evolución (c) Consejo Superior de Investigaciones Científicas Licencia Creative Commons 3.0 España (by-nc) de la red viaria y transformación del paisaje, los resultados obtenidos no permiten establecer unas conclusiones excesivamente claras; tan sólo se observa una cierta tendencia a la asociación entre valores altos de cambio de infraestructura y de cambio de paisaje; la combinación cambio alto de infraestructura/cambio positivo en el paisaje, por el contrario, no se da en ningún caso.

Dentro de la clase 1 de cambio de infraestructura (no hay cambio), que concentra la mayor parte del territorio, se observa que la mayoría de la superficie se sitúa en la clase 6 de cambio de paisaje (no hay cambio).

$3^{a}$ Las conclusiones comentadas parecen reforzar la hipótesis que relaciona el cambio de la red viaria con la transformación del paisaje, si bien esta conclusión debería ser contrastada mediante el empleo de otros índices que midan la calidad de las infraestructuras y su evolución, y tengan a su vez, como ya se ha comentado, un mayor poder discriminatorio.

\subsection{BIBLIOGRAFÍA}

BAKER,W.L., 1989. A review of models of landscape changes. Landscape Ecology Vol.2-2. pp.111-133.

BARROW, C.J., 1991. Land degradation. Cambridge University Press.

CAM, 1986. Memoria del mapa ftsiográfico de Madrid. Consejería de Agricultura y Ganadería. Comunidad Autónoma de Madrid. 
CAM, 1987. La Naturaleza de Madrid. Consejería de Agricultura y Pesca. Comunidad Autónoma de Madrid.

COPLACO, 1974. Mapa de usos de suelo de la provincia de Madrid. Madrid.

22 ESRI, 1992. Understanding GIS. The ARC/INFO Method, PC version. ESRI, New York.

FORMAN, R.T. \& GODRON, M., 1986. Landscape Ecology. John Wiley \& Sons, New York.

HELMER, O., 1966. The DELPHI method for systematizing judgements about the future. Univ. California. Los Angeles.

LIZET, B. \& RAVIENAN, F., 1987. Comprendre un paysaje. INRA, Paris.

MEEUS, J.H.A. et al., 1989. Agricultural landscapes in Europe and their transformation. Landscape and Urban Planning Vol.18. pp.289-352.

MOPU, 1985. Evolución de los paisajes y ordenación del territorio en Andalucía Occidental. Instituto del Territorio y Urbanismo. MOPU-Casa Velázquez. Madrid.
NAVEH, Z. \& LIEBERMAN, A.,1984. Landscape Ecology. Theory and aplication. Springer-Verlag. New York.

SKLAR, F.H., 1990. A plygon-based spatial (PBS) model for simulating landscape change. Landscape Ecology, Vol.4- 2/3. pp.83-97.

TURNER, M.G., 1987. Spatial simulation of landscape changes in Georgia: a comparison of three transition model. Landscape Ecology, Vol. 1-1. pp.29-36.

VARIOS AUTORES, 1981. Persectives in Landscape Ecology. Proceedings of International Conference of Landscape Ecology. Veldhoven, The Netherlands Centre for Agricultural Publishing and Documentation. Wageningen.

VARIOS AUTORES, 1982. Mapa de la vegetación y usos actuales del suelo de la Comunidad de Madrid. Escala 1:200.000. Diputación Provincial de Madrid.

ZONNEWELDI, J.S. \& FORMAN, R.T.T., 1989. Changing landscapes. An ecological perspective. Springer-Verlag. New York.

\section{publicación del ICCET/CSIC}

\section{INSPECCION DE OBRAS DAÑADAS POR CORROSION DE ARMADURAS}

\footnotetext{
El presente Manual va dirigido principalmente a técnicos especializados y laboratorios que tienen que intervenir en el dictamen de la situación de deterioro de estructuras de hormigón armado dañadas por corrosión de armaduras.

Comienza con un resumen recordatorio de los factores principales a los que se pueden deber los daños prematuros por corrosión de armaduras, para seguir con algunas indicaciones de cómo se deben realizar las inspecciones, y de los ensayos y la metodología que se recomienda realizar para poder dictaminar con precisión las causas de daño.

A continuación se hacen una serie de comentarios sobre la vida residual de estructuras dañadas, sobre el riesgo de corrosión futura, el seguimiento necesario de una estructura reparada y una breve enumeración de métodos de reparación y consideraciones básicas a tener en cuenta en la recomendación de un determinado método. Se aporta una breve relación bibliográfica.

Finalmente se incluyen en forma de ficha la descripción de algunos casos de corrosión de armaduras detectados en nuestro país.
}

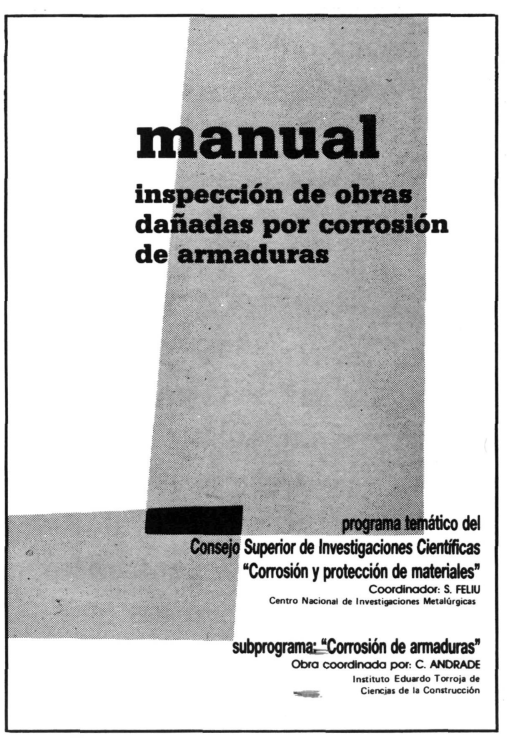

